\title{
Interdisciplinarity in New Product Development in an Indian MedTech Perspective: Gap and the Solution
}

\author{
Vijayarajan Alagumalai ${ }^{~}$ Pooja Kadambi ${ }^{1}$. Abhishek Appaji ${ }^{2,3}$ (D)
}

Received: 2 April 2019 / Accepted: 12 June 2019 / Published online: 11 July 2019

(C) The Author(s) 2019

\begin{abstract}
The medical device industry is a niche field globally and among the fastest growing industries in India. It requires specialised and interdisciplinary skills, as well as knowledge for innovation of new product development. New product development has four key phases: need finding, concept generation, engineering and validation. The first two phases require broad vertical and lateral thinking to come up with innovative plus appropriate solutions. Thus, multidisciplinary teams made up of experienced individuals with interdisciplinary knowledge enhance the phase outputs. The next two phases are iterative, usually requiring management of multiple subsystems, across technical disciplines and system integration. Without interdisciplinary product members and technical leaders, product development is not optimised. This leads to numerous iterations - loss of time, money. The industry struggles to find these interdisciplinary resources and building this capacity today takes a decade in India, with the entire burden falling on the industry. In well-developed medical device markets, higher education has introduced application-centric courses with cross-disciplinary curriculums. Such a structure allows students to gain valuable skills and understanding of the industry as a whole. Developed ecosystems have no shortage of experts available who serve as technical leaders. Developing countries like India have a very young indigenous medical device industry. In such nations, private companies struggle to find experienced individuals capable of interdisciplinary thinking and problem-solving. In this paper, we present India's current Medtech perspective, and the industry member's experiences through case studies and interviews. An outline for an academic model to meet the requirement of the industry has been presented.
\end{abstract}

Keywords Medical Devices $\cdot$ Medtech $\cdot$ Systems engineering $\cdot$ Interdisciplinary

\section{Introduction}

Despite the high regulation and financial pressures on the medical industry, the global medtech market is growing. The industry is currently valued $\$ 389$ billion and is expected to reach $\$ 483.8$ billion in 2022. The Indian domestic market (with $85 \%$ imports) is now only about $\$ 10$ billion but projected to cross $\$ 20$ billion in the next 5 years. Accessibility and affordability to quality healthcare is a critical need for India; indigenous development of medical

Abhishek Appaji

abhishek.appaji@maastrichtuniveristy.nl

1 InnAccel Technologies Pvt. Ltd, \#4 Aanand Tower, Raja Rammohan Roy Rd, Sampangiramanagar, Bangalore 560025, India

2 Maastricht University, Maastricht, the Netherlands

3 B.M.S. College of Engineering, Bull Temple Road, Basavanagudi, Bengaluru, Karnataka 560019, India devices and diagnostics must be supported [1]. The government, through infrastructure, grants, and the "Make in India" initiative, are trying to help the medical technology space [2]. Unaddressed gaps observed in India include low accessibility, low ability to pay, inadequate regulatory systems, lack of customisation and innovation, as well as insufficient attention by policymakers [3]. There is also a lack of a Medtech industrial network that has professionals with interdisciplinary skills to drive medical product development. Finding appropriately qualified graduates is challenging. Furthermore, there is a need to extensively train new hires to perform a meaningful role in medical device creation. This exercise is an expensive and slow process. The burden of such capacity building falls solely to a currently small and underdeveloped industrial ecosystem. The need for indigenous Medtech industry growth is significant, but the challenges faced on multiple fronts are creating barriers. These barriers need to be addressed by academia, industry, and the government. 
In the last five years, many tech-parks have been initiated in India to help build the Medtech ecosystem. Andhra Pradesh MedTech Zone (AMTZ) is an example of such a set-up. AMTZ facilities were established by the Indian government with much private industry and academic collaborators. They house over 80 medical device manufacturers and are expected to have more than 200 manufacturers shortly. Such a concentration of specialised resources with expertise is designed to increase interdisciplinarity and access to niche industry requirements. This is a promising step towards the growth of the Indian Medtech ecosystem [4].

\section{Background}

The term multidisciplinary is defined as combining several academic disciplines and professional specialisations [6]. Forming a team of individuals each with one or more core areas of expertise to achieve goals, typically produces multidisciplinarity. Each may have little to no knowledge of the other member's field/s. On the other hand, interdisciplinary is a term that refers to the same individual or academic area that contains more than one branch of knowledge [7]. How different departments are defined, and how closely they are related are subjective. Thus, a multidisciplinary approach adds people to build a collective knowledge base, while interdisciplinary develops expertise/experience within individuals to add not only knowledge but also create new perspectives. In diverse fields that require holistic approaches to problem-solving, the more each member knows about the various facets of the product, the better the project outcome. There is also a lesser likelihood of missing critical insights [8].

Medtech is such a multidisciplinary/interdisciplinary space that integrating systems to meet technical, regulatory, clinical, manufacturing needs, and so on is challenging [9]. The field of biomedical sciences/engineering/ technology was created to address these challenges. Biomedical engineering is an interdisciplinary course that applies the concepts, knowledge, and techniques of virtually all engineering disciplines to solve specific problems in health care, at a system level [10]. Figure 1 represents the diverse and complex fields that are part of the biomedical family. Some examples of intricate areas of research where such interdisciplinary skills are necessary to tie things together include:

- Sonar acoustic technology is the foundation of diagnostic ultrasound. This field relies heavily on signal processing and audio engineering. It also requires a deep understanding of tissue properties, physics, as well as patient and user interfaces [11].

- Artificial heart valves and artificial blood vessels rely heavily on the merger of anatomical and physiological knowledge with complex mechanical, electrical, and electromechanical systems. Understanding fluid dynamics, tissue reaction to materials and tissue wall strength are crucial to development in this area [12].

Typically, product development involves multiple iterations and phases. In this paper, we are considering two main phases, the "concept generation" phase and the "development and testing". The Concept Generation phase, known as Fuzzy Front End (FFE), is creative, and the integration of different sources of knowledge makes it more complicated. It is iterative as well as non-linear. The more interdisciplinary work conducted during FFE, the more successful the stage will be, and the fewer the surprises one will encounter in the subsequent phases [13].

The Development and Testing phase stage starts with system design and involves the deconstruction of the system into sub-systems and to separate components. These subsystems and components can be developed independently. The system design will also define the interfaces where the parts interact. Such design parameters include shapes, dimensions, and connection characteristics, such as currents, digital signals, fluid pressures, and forces. This will highlight critical interfaces, dependencies, and constraints with the system [14]. The development teams are typically organised by functional discipline. Once the system design has been established, the various team members proceed to work on the subsystems and components of the product, separately. Following this, component level testing, integrated testing, bench testing, cadaver testing and final clinical validation of the product is performed with various cross-team involvements before full-scale production launch. The pathway to successful device development is cyclical and iterative as components are prototyped, tested, improved, re-tested, integrated, tested, optimised, and finalised. Figure 2 outlines the phases of product development and a representative team structure to illustrate the nature of Medtech, indeed any system development. Systems engineering and interdisciplinary skills across team members play a critical role in a mixed discipline environment like Medtech.

The International Council on Systems Engineering defines systems engineering as "an interdisciplinary approach and means to enable the realisation of successful systems." Sarah A. Sheard of the Software Productivity Consortium said it best: "The systems engineer is the 'owner of glue' among subsystems, the seeker of issues that fall in the cracks, the 'technical conscience' of the program" [15]. Today, in India, an appropriately qualified individual rarely fills the role of System Engineering. Currently, the position is typically filled by Senior designers or Technical managers. Such individuals, while experienced in their specialized areas, often lack the interdisciplinarity required to drive the product development process efficiently. This non-availability of suitable system 


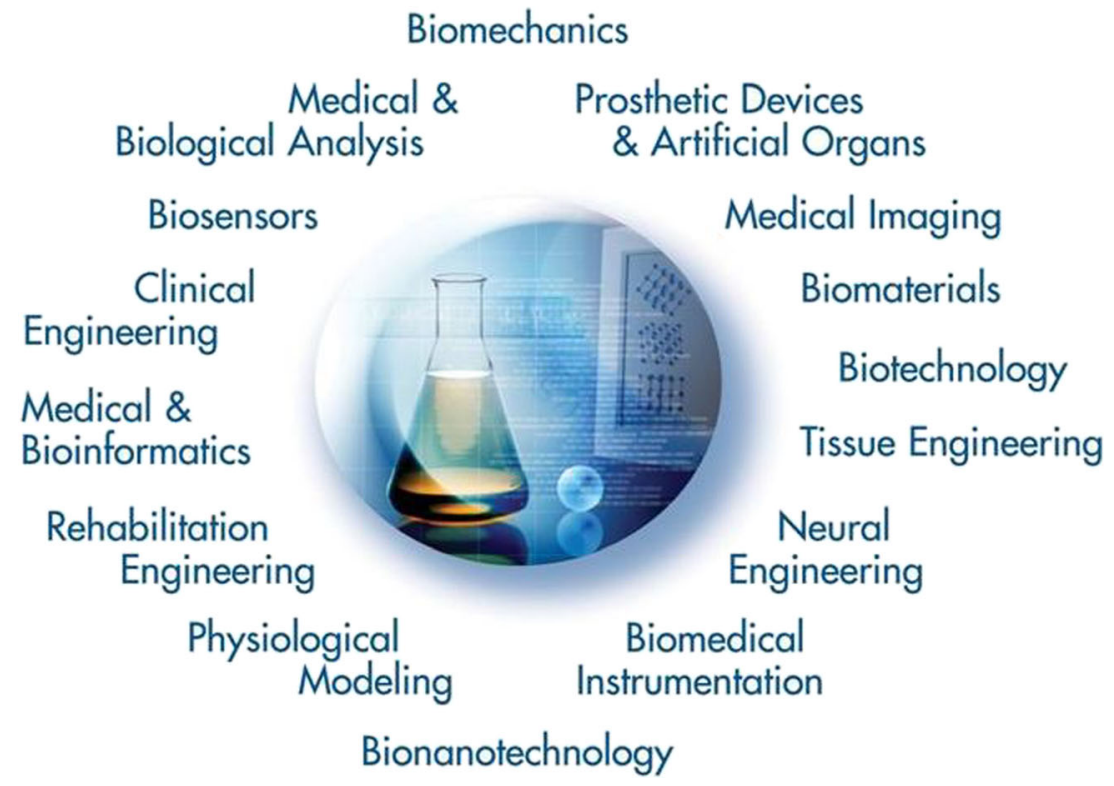

Fig. 1 The world of biomedical engineering [5]

engineering resource leads to issues at a project level during later stages.

Experienced developers who excel in a single technical area tend to focus on their part of the product and often can lose sight of the bigger picture. Significant product development issues occur when the components come together as a system. Without a system-level perspective with interdisciplinary skills, troubleshooting at a product or system level becomes tedious and often impossible [16, 17]. For example, most of design and development team members lack interdisciplinary knowledge of regulatory requirements. Such a gap results in significant rework on the design and increasing the cost at a later stage. Also, since clinical experts have busy practices, there is often no ongoing engagement of clinical

\section{Concept Generation}
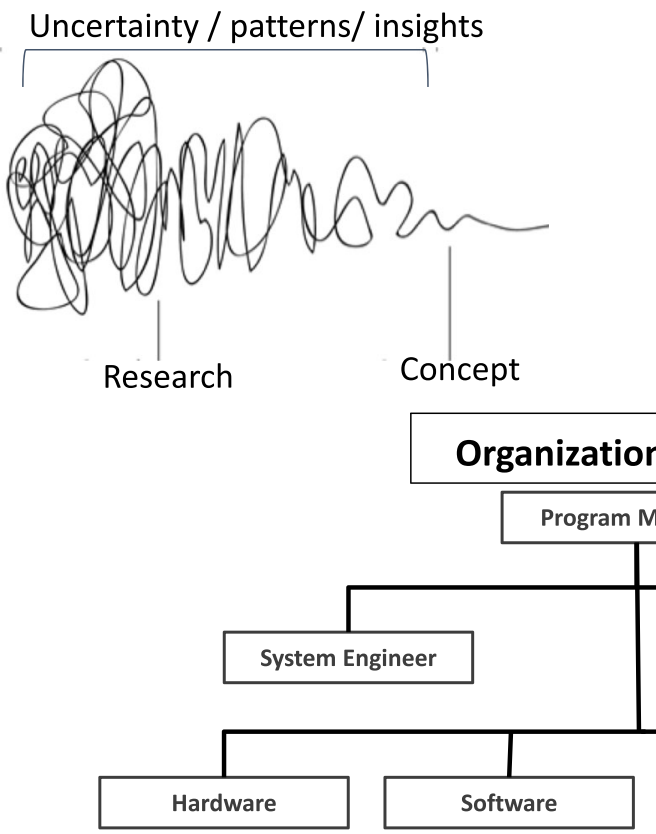

Fig. 2 Phases of product development and organisation structure

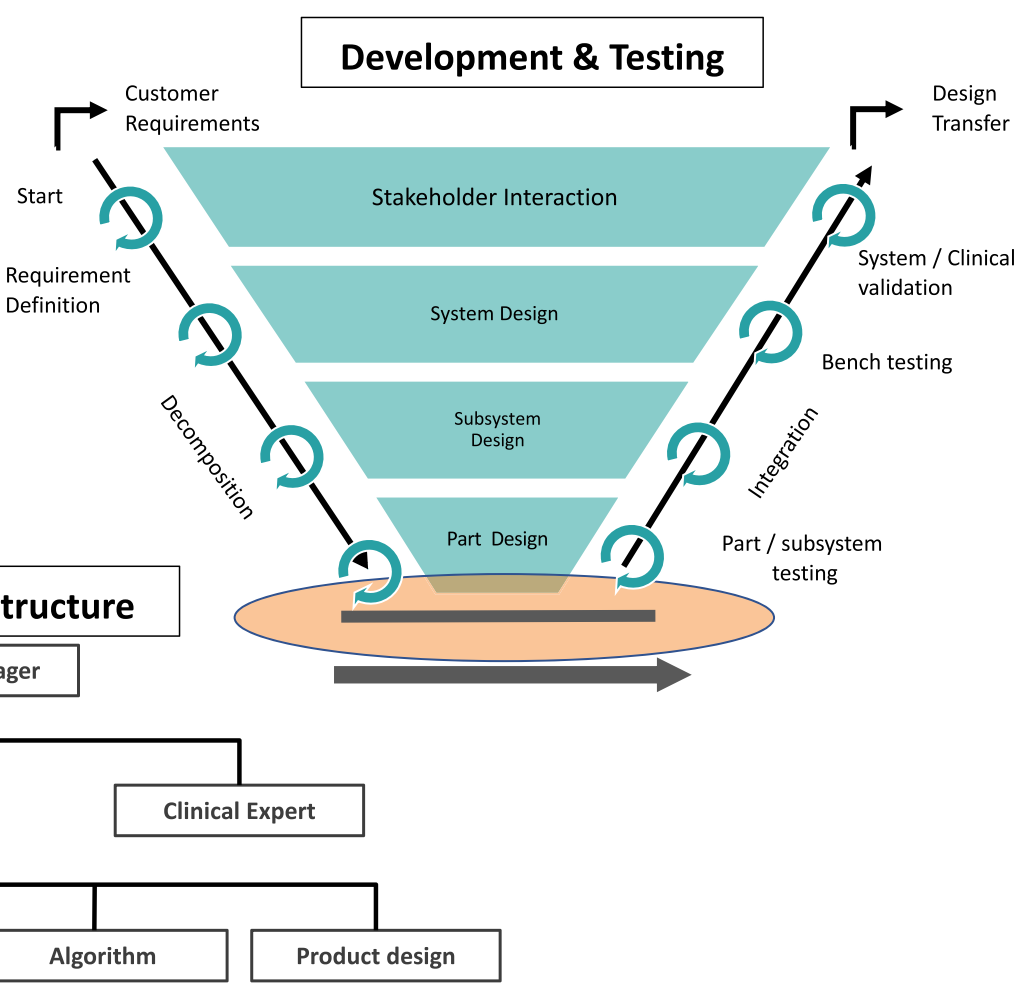


experts during the development stage. Without some interdisciplinary knowledge of the clinical field and relevant terminology, each interaction with a clinician is less meaningful [18-20]. Often, the interpretations of specifications itself go wrong, or essential requirements missed completely. Such oversights lead to the end product falling short of expectations during final validation. Thus, through building core interdisciplinary skills among team members and having a reliable interdisciplinary systems engineer, a common framework of critical knowledge can be created, and high-quality products developed in both a time and a cost-effective manner. Also, multidisciplinarity without interdisciplinarity will prevent a team from achieving its full potential.

\section{Methodology}

This paper represents a perspective that was put together by considering the authors' field experience, published literature, and generated data. The data presented comes from three sources:

- An indigenous Indian medical device case study. Data was gathered by interviewing key members of the development and management team.

- A survey of Indian Medtech professionals. Qualitative and quantitative data were gathered through interviews with practising Indian medical device engineers and designers.

- A survey of Indian academia faculty. Qualitative and quantitative data were gathered through interviews with active professors in one state of India (Karnataka) from various departments and universities.

Professional online websites, news articles, publications, and textbooks were the sources for industry research. This research was primarily used to provide background information, design the data collection instrument, and build the proposed education model. No formal statistical analysis was planned, and only descriptive statistics have been presented. This paper had no specific hypothesis question and had a more exploratory approach to research.

\section{Medical device development case study}

Fetal Lite is a compact, wearable and intelligent contraction stress test and non-stress test monitor. It is designed for easy, effective and comfortable monitoring of fetal and maternal parameters post 36 weeks of gestation and during labour [21]. Fetal Lite is a CE (European Union) certified product that was developed by Sattva Medtech, an Indian start-up company [22]. Figure 3 shows the product, its critical components, and interfaces.
The product development team composed of six core members was led by an experienced engineering program manager and was functionally organised. The group included members for embedded systems, software, algorithm development, product design (including the user interface), and regulatory compliance. The team had access to clinical and technical experts on a consultancy basis. The core development team had only between 1 to 3 years of work experience. The engineering program manager and regulatory expert had more than 15 years of experience each. There was no biomedical engineer or mechanical engineer on the team. The only interdisciplinary expertise was within the embedded group that had knowledge and expertise in hardware and software, particularly firmware. Minimal system engineering expertise and Medtech domain knowledge were available to the team.

An incremental and iterative stage-gate development process was followed, keeping with the globally accepted quality and safety standards (ISO 13485, ISO 14971). The team took the product from proof of concept (POC) through Alpha prototypes, Beta prototypes, and final production. Post proof of concept external partners and consultants were engaged to support the team for development. The team did the verification, and validation testing obtained quality certification and handled the design transfer for manufacturing. They have utilised a contract manufacturing vendor for production of the product. A thorough analysis of the product development pathway with the team identified gaps and inefficiencies that could have been handled differently in hindsight. Two pivotal instances were chosen for discussion in this paper.

\subsection{Signal quality challenge}

The team was focusing on improving the technical design of the product to enhance the quality of biosignals being captured. The following clinical realities were missed:

- There is an insulating layer called vernic caveosa that forms in a pregnant woman in the 31 st week of gestation. This not only impacts the strength of the signal being captured but also adds noise to it.

- Fetal ECG conducts through dynamic multi-medium layers like tissue and amniotic fluid rather than a single medium.

- Anatomically, the optimal location on the mother to pick up Fetal ECG varies with baby position and the physiological properties of the mother's abdomen.

- Dead skin introduces high electrical signal impedance, making skin exfoliation a necessary step in capturing accurate signals at the sensor surface.

A lack of knowledge of the clinical environment, human biology and research methodology was the root of the issue. Having a biomedical engineer or full-time physician as part of 

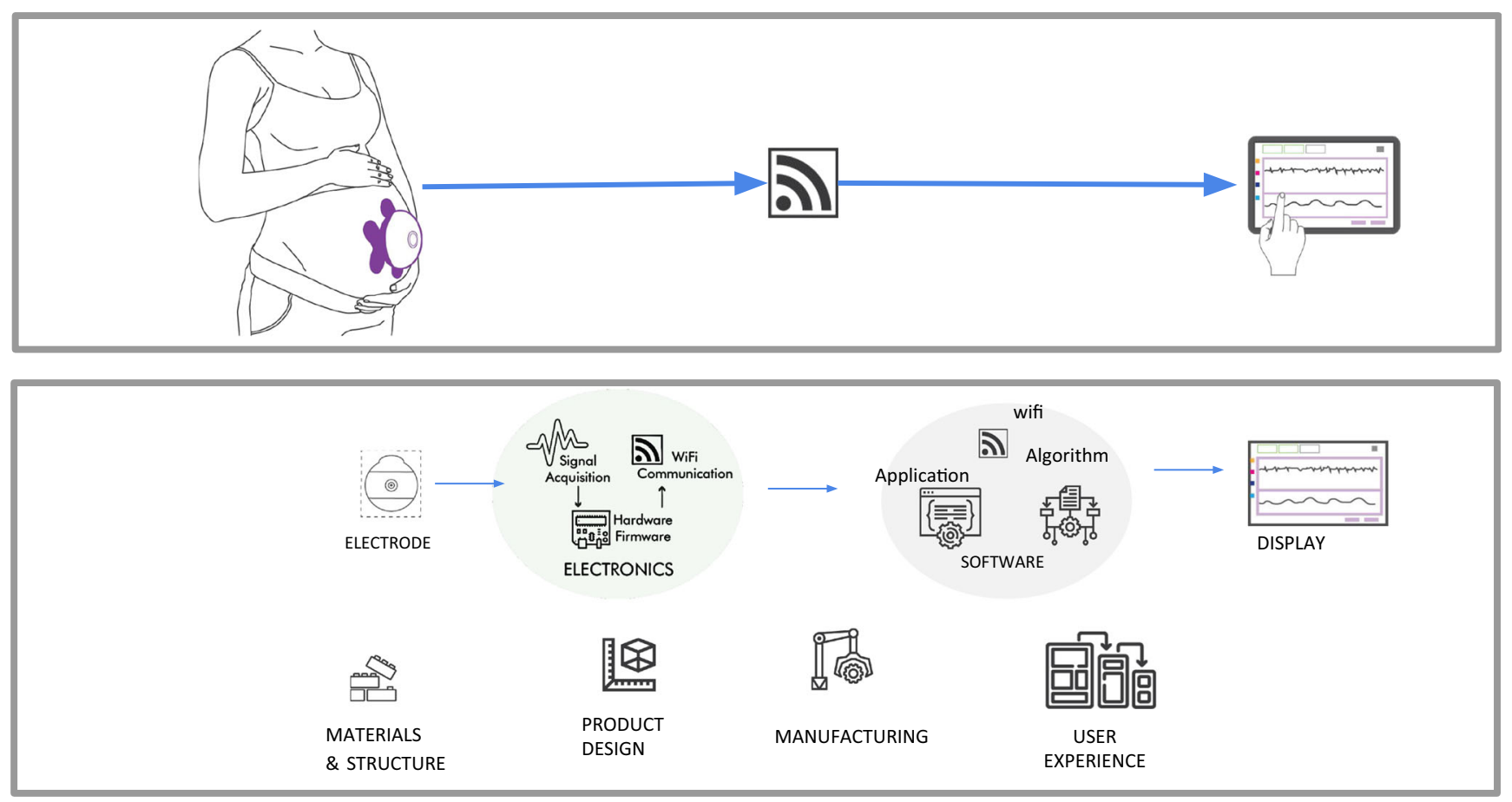

Fig. 3 Fetal Lite System Architecture

the team would have helped. Also, spending the time upfront, in building interdisciplinary knowledge within the team would have likely saved time and money overall through comprehensive specification creation, efficient experimentation and fewer prototyping cycles.

\subsection{Data loss challenge}

Fetal Lite had a problem during the transmission of acquired data to the tablet. The delayed reception of TCP packets and intermittent drop in connection resulted in significant data loss at the tablet. To remove the data loss, the team used its core expertise in implementing optimizing algorithms. But the root cause of the problem was a networking domain issue.

Even after identifying the problem, it was not easy to mitigate it. After multiple rounds of testing, the team realized that the performance of the system was utterly dependent on firmware running in the WiFi Module, which was proprietary and not open for third parties. At this point, a customized firmware was optimized for the specific use case of the Fetal Lite system.

Thus, the root cause of the issue was not identified at the beginning. Efforts were wasted in working on different components and sub-systems that each member knew individually. More expertise in communication networks and an understanding of system level impact would have aided the problem solving and product development. By having a more profound knowledge of components and interfaces across individuals, an interdisciplinary approach to problem-solving may have proved successful leading to saved time and efforts.
It was concluded that a lack of experience, especially the interdisciplinary exposure, lead to delays of at least six months in the 42-month product development lifecycle ( $\sim 15 \%$ delay). The need for additional hiring and training during the project took time away during later stages and impacted the project as a whole. The team concluded that system level knowledge and thinking must be incorporated throughout the process and across functions for efficient development and troubleshooting.

The program manager indicated that it took 6-8 months at least to train the team to contribute to developing medical products in a meaningful way. Such a training timeline is especially true in a start-up environment where the demand for interdisciplinary learning and performance is high. Hence it does seem possible to train and create interdisciplinary capacity and system level engineering thinking within six to twelve months depending on the individual and methods of teaching/training. Such a finding is a positive indication that academia with industry partners should be able to produce such engineers.

\section{Industry perspective}

25 Industry professionals with a background in engineering and product design were surveyed. Questions covered their current role and academic coverage of relevant topics. The demographics of participants are represented in Table 1 below. The survey included concept generation, detailed engineering and design, verification and 
Table 1 Demographics of Industry professions

\begin{tabular}{ll}
\hline Category & Value \\
\hline Gender & $80 \%$ Male, 20\% Female \\
$\begin{array}{l}\text { Product Architect } \\
\text { Role }\end{array}$ & $56 \%$ Yes, 40\% partial, 4\% No \\
Academics & $\begin{array}{c}100 \% \text { had Bachelors and } 84 \% \text { had higher degrees. 84\% had a full education in India. 28\% } \\
\text { had some degree in design and } 80 \% \text { in engineering. } \\
\text { Experience }\end{array}$ \\
$\begin{array}{c}\text { Average experience in Medtech 11 years (1-40 range) with 25\% in medium and 25\% in } \\
\text { large and 50\% in small companies. }\end{array}$ \\
\hline
\end{tabular}

validation testing, and design transfer activities. Figure 4 represents activities that a significant majority of those surveyed perform as part of their current role, along with the rate to which such actions were covered in the Indian Engineering system. The difference between what work people were trained to do and what they need to do in the workforce represents a lack of preparedness through formal education. Slightly higher values were seen for concept generation, applied engineering/design and manufacturing activities when those who studied abroad and designers were considered. However, education providing awareness of testing and regulatory compliance remained low across most individuals.

When asked how they made up for the deficits in learning, $100 \%$ of those surveyed said through on the job learning; 92\% stated through self-education and 25\% through peer to peer learning and mentorship. Figure 5 shows the average rating across those surveyed when asked to rate their level of preparedness (1-5) to drive product development from concept generation through design transfer. As seen in Fig. 5, the confidence rating of those surveyed is high currently but was low after their undergraduate $(\mathrm{UG})$ as well as their postgraduate $(\mathrm{PG})$ education.

Figure 6 represents the participants rating of crucial aspects of their educational experience in Indian Engineering Colleges. The average score was low. Those individuals who went abroad for education rated all these aspects as 4 or 5 . When asked what academia could do to better prepare students for the Medtech or any product development industry, $100 \%$ of those surveyed stated offering specialised electives with the flexible curriculum as a must. $88 \%$ of respondents said mandatory industry engagement and a higher focus on practical/applied education was necessary. Majority of those surveyed also suggested updating the curriculum, faculty knowledge and incorporating team projects.

There was also a clear gap identified in the exposure to safety, legal and regulatory requirements in medical devices. It is vital for students to understand verification for medical devices, to ensure safety and satisfy the regulatory authorities. The processes and procedures required for the approval of various medical devices have to be included in the syllabus to understand not only ethical but the legal

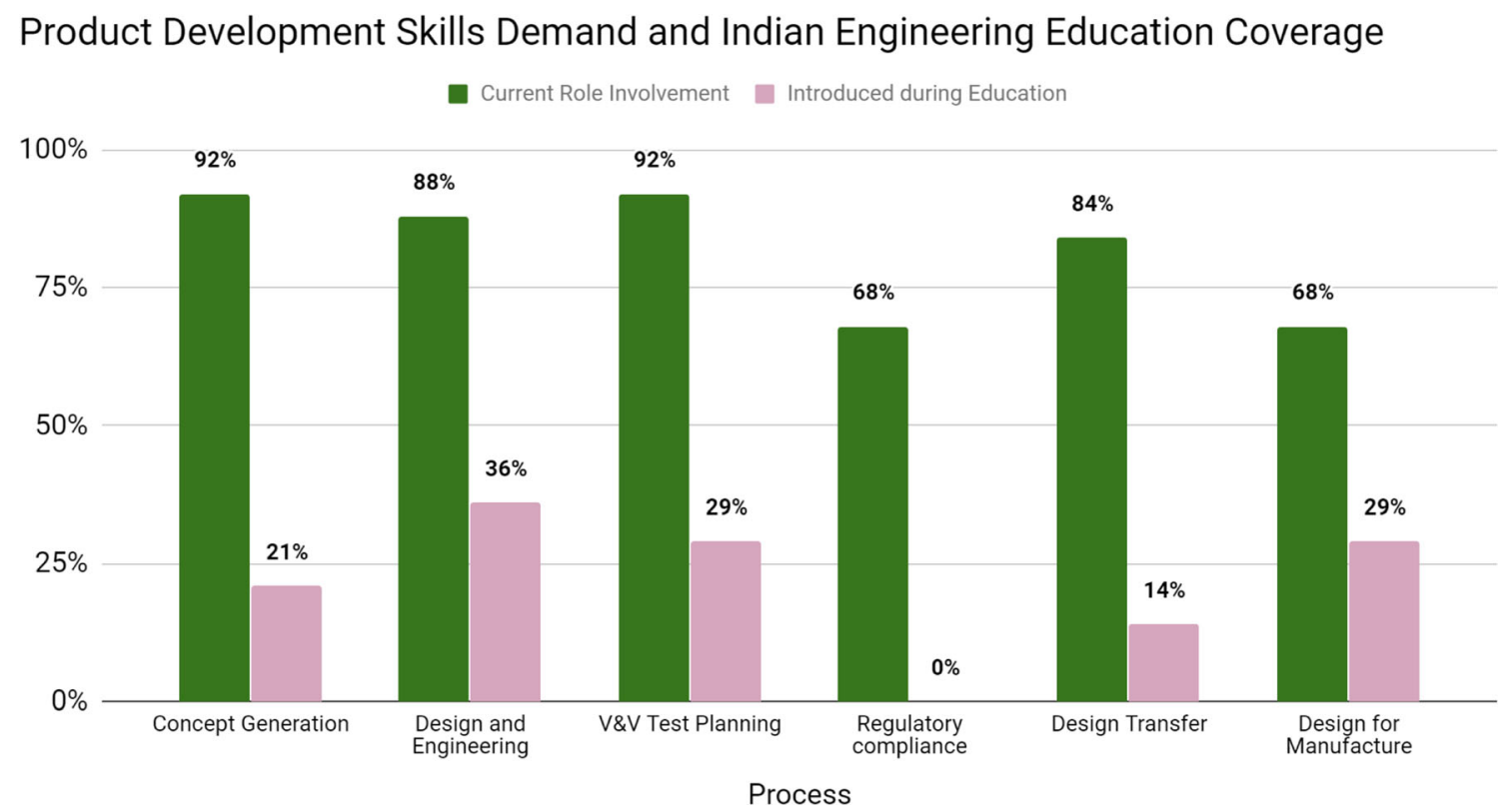

Fig. 4 Product development skills demand and Indian Engineering education coverage 


\section{Rating on Preparedness to be product Architect}

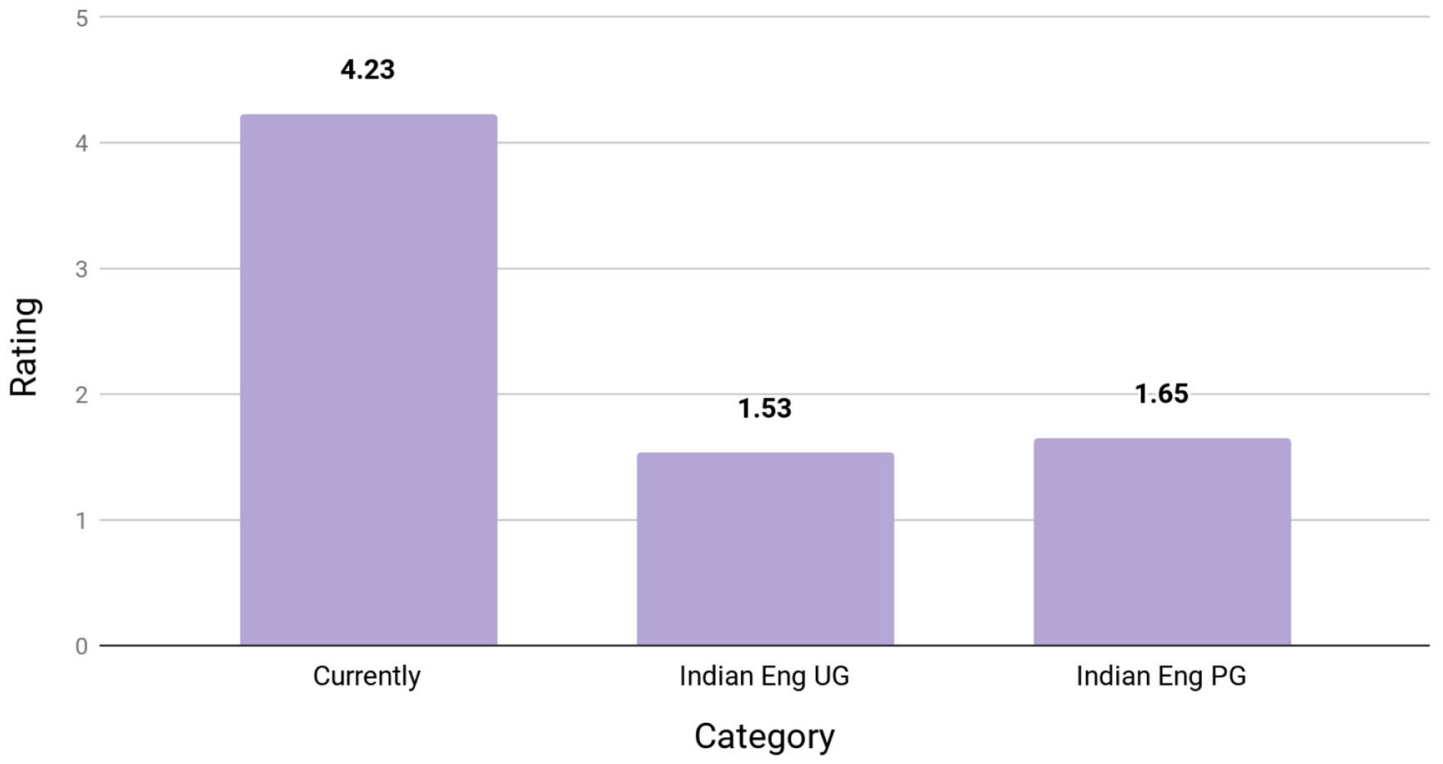

Fig. 5 Average rating on preparedness to be product architect at different stages of career and education

requirements, locally and globally. Performance verification plays an essential role in increasing the efficiency and reliability of patient diagnoses, treatment and cure. There are well-established documents available with USA Food and Drug Administration (FDA) or European Union $\mathrm{CE}$ agencies as well as the Indian regulatory body Central Drugs Standard Control Organisation (CDSCO) who currently regulates some notified medical devices [20].
Looking at the data, it is clear that the burden of training and skill development for the role of product architect or systems level engineering falls entirely to the industry. The creation of institutes like Kalam Institute of Health Technology (KIHT) could help reduce the burden on institutes and companies to invest in expensive infrastructure, and capital equipment. It also has started with India Biomedical Skills Consortium (IBSC) certification program which gives

\section{Rating of Indian Engineering Students on Education}

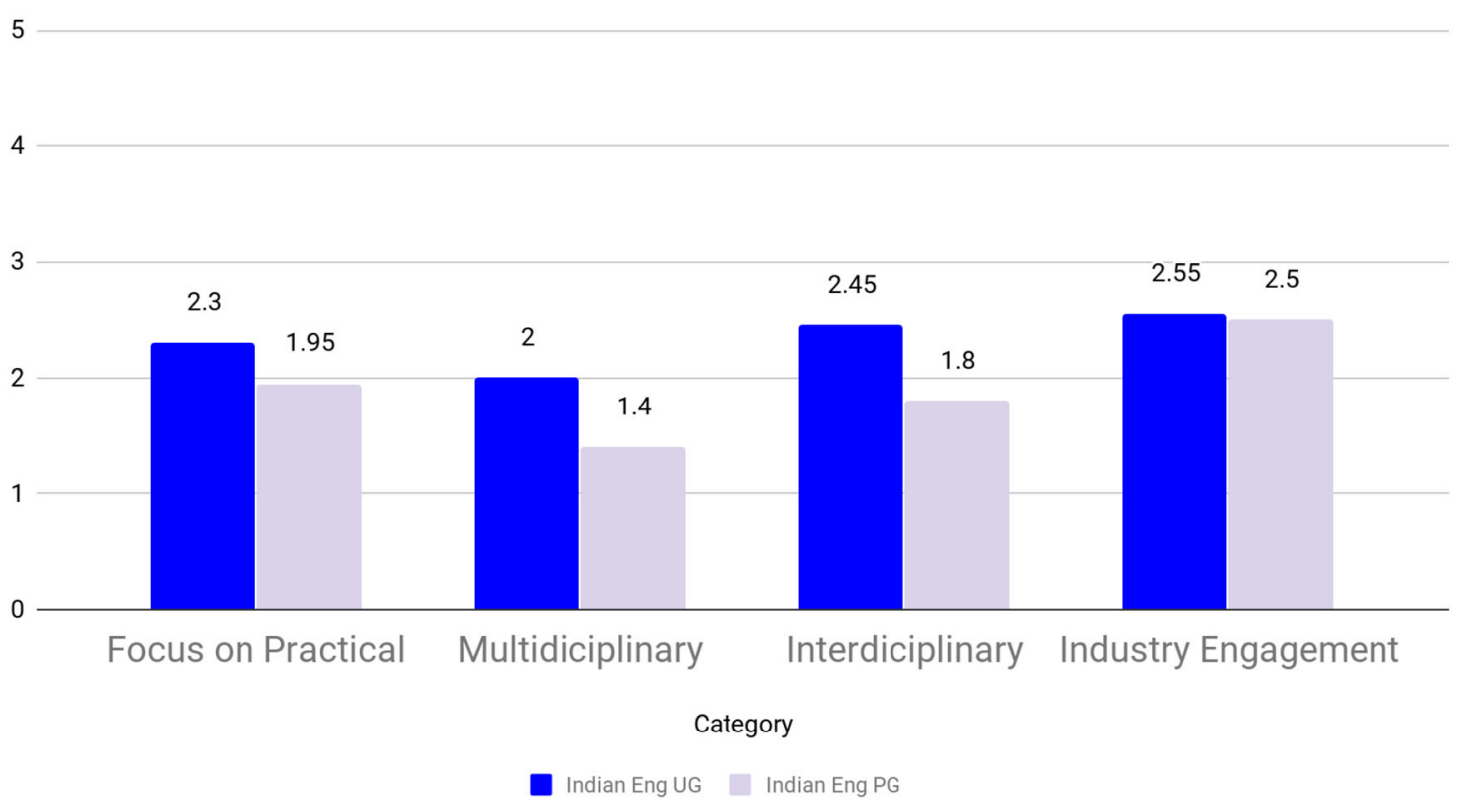

Fig. 6 Average Rating on Education Incorporation Beyond Theory 
a holistic approach for individuals working in the manufacturing of medical devices as well as support during and after sales $[4,23]$. The certifications available through IBSC could be a way to uniformly qualify students in specific areas required in Medtech like Anatomy and Physiology, Clinical research, Biomaterials, and so on.

\section{Academia perspective}

The academic perspective was captured through interviews participated by 15 experienced academicians. The demographics of participants are represented in Table 2 below.

The participants were interviewed about interdisciplinary and multidisciplinary courses offered in engineering education in their respective institutes and in general, in India. The model, as shown in Fig. 7, was introduced to the participants, and their opinions were gathered on its feasibility and barriers.

Key results from the survey were as follows:

- $93.3 \%$ stated that sufficient focus is currently given to applied/practical engineering in the courses.

- 53\% academicians reported that sufficient industry engagements were present

- $73.3 \%$ of those surveyed said that the engineering schools offered ample options in terms of electives. However, these options were limited to within the specific departments and were not genuinely interdisciplinary.

- Only $40.0 \%$ said that multidisciplinary projects were feasible.

- $73 \%$ of academicians wanted a flexible curriculum with interdisciplinary and multidisciplinary courses provided as options.

- $66.6 \%$ believed that the proposed model was highly viable, and $26.5 \%$ felt that it was somewhat feasible.

Some key insights on the current academic curriculum structure, limitations and model implementation in the Indian context were gathered. Professors agreed that courses are focused mainly on theory and fundamentals. However, they believe that one project and internship was enough in terms of applied or practical engineering. Academicians also felt that interested students were able to successfully engage with industry, though without much facilitation from academia. Those surveyed also agreed that undergraduates are given a "flavour of everything" without a deep understanding of many topics. However, all professors felt that the rigidity of the curriculum and lack of multidisciplinary and interdisciplinary options were due to university constraints and lack of inter-departmental cooperation within the institutes.

The challenges in implementing changes to the current curriculum were stated as follows:

- Limited influence on the profile of students admitted to courses

- Lack of expertise among faculty to handle new courses

- Lack of academic motivation and career clarity for postgraduate students

- The absence of a shared vision between academia and industry

- Government and Educational board policies are not dynamically updated

Most academicians did not believe that Medtech required a new program or a niche undergraduate program. They find an approach of offering electives and additional semesters to get a specialisation certification would be a better option. Some also stated that this should be industry driven. Thus, the proposed model will need to be modified to take into account available resources, institutional rules, government policy and the student benefits.

\section{Proposed solution}

While there are many approaches to interdisciplinarity, a fiveyear model has been suggested here that represents the initial insights from both Indian Engineering Academia and the Medical Device industry. Table 3 depicts a curriculum for the few interested and capable students to achieve higher industry readiness without putting too much of a burden on the existing system.

The outlined program was modelled after successful programs in the USA and the UK (Johns Hopkins
Table 2 Demographics of Academicians Surveyed

\begin{tabular}{ll}
\hline Category & Value \\
\hline Gender & $60 \%$ Male, 40\% Female \\
Academic system & 8 Engineering Institutes in Karnataka (7 part of VTU system (6 with autonomy), 1 deemed \\
& university) 5 departments of engineering \\
Academic & $100 \%$ had taught for a minimum of 5 years with the average level of experience being \\
Experience & 20.5 years in academia. \\
Industry & 33\% had had no experience in or with industry and 30\% had at least two years of industrial \\
Experience & experience.
\end{tabular}


Master Level Interdisciplinary Program to create Product Architects

Core Discipline + one or more related disciplines

\begin{tabular}{|l|}
\hline \multicolumn{1}{|c|}{ Semester 1} \\
\hline - Advanced Courses in core \\
discipline \\
- Prerequisite courses in \\
related disciplines \\
- Introduction to product \\
development cycle and \\
method
\end{tabular}
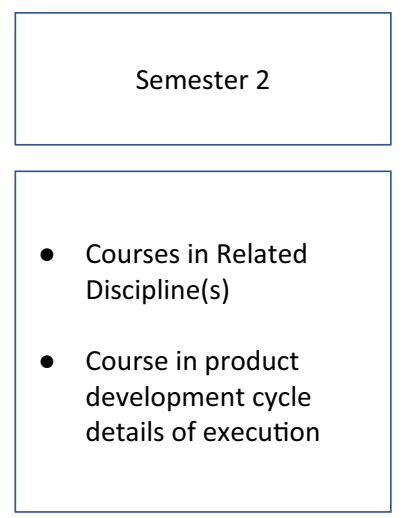

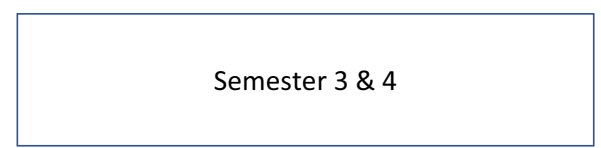

- Thesis by Project (multi disciplinary in nature. Preferably a product)

- Professional Practicum Training (preferably with industry engagement)

Fig. 7 Curriculum model shown to academic participants

University, USA, University of Cincinnati, USA and Oxford University, UK). The Indian Medtech industry is still small and does not require many niche engineers. We believe that training those with a strong core background in electronics, mechanical, software, and so on is the solution. The gap in the industry can be met, and students will gain more avenues for further education and careers. Course objectives would include integrating the knowledge of traditional engineering disciplines and modern biology to solve problems encountered in living systems:

Learning Outcomes:

- Expand knowledge in other engineering disciplines to gain a system-level understanding of MedTech - acquire interdisciplinary skills.

- Design a system, component, or process to meet desired needs with realistic constraints such as economic, environmental, social, political, ethical, health and safety, manufacturability, and sustainability.

- Ensuring understanding of quality compliance methods with global ethical and quality standards as well as legal requirements for medical devices.

- Effectively function in multidisciplinary teams.

Infrastructure requirements would include a Medtech lab as well as access to core traditional engineering labs (mechanical, electrical, electronics, computer science, chemical engineering) on campus. Also required is access/collaboration with traditional engineering disciplines as well as to a clinical environment. The presence of faculties/advisors/Mentors from Medtech industry \& practising clinicians is also essential. MedTech zones like AMTZ could also incorporate training and industry exposure with academic institutes to supplement classroom learning and theory. Incorporating IBSC certifications or testing the expanded knowledge of students

Table 3 Proposed Curriculum Model for Hybrid Undergraduate Course

\begin{tabular}{|c|c|c|c|}
\hline & Electronics Engineering & Mechanical Engineering & Computer Science \& Engineering (CSE) \\
\hline Core Discipline Courses & \multicolumn{3}{|l|}{ As is today } \\
\hline Interdisciplinary Electives & $\begin{array}{l}\text { Related courses from Mechanical } \\
\quad \& \text { CSE }\end{array}$ & $\begin{array}{l}\text { Related courses from Electronics } \\
\quad \& \text { CSE }\end{array}$ & $\begin{array}{l}\text { Related courses from Electronics \& Mechanical } \\
\text { Engineering }\end{array}$ \\
\hline BioMed Core (mandatory) & $\begin{array}{l}\text { - Intro to Bio Medical } \\
\text { Engineering }\end{array}$ & $\begin{array}{l}\text { - Regulatory requirements } \\
\text { - Physiology for engineers }\end{array}$ & \\
\hline $\begin{array}{l}\text { BioMed Specialization } \\
\quad \text { (choose one) }\end{array}$ & $\begin{array}{l}\text { - Bio Medical Instrumentation } \\
\text { - Bio Mechanics \& Rehabilitation }\end{array}$ & $\begin{array}{l}\text { - Bio Medical Imaging } \\
\text { - Medical Robotics }\end{array}$ & \\
\hline 3rd Year Project & \multicolumn{3}{|c|}{ Design/engineering + testing project for a finalized concept } \\
\hline 4th Year Project & \multicolumn{3}{|c|}{ Needs finding/understanding/assessment exercise + concept generation } \\
\hline 5th Year Capstone Project & \multicolumn{3}{|c|}{$\begin{array}{l}\text { - Do a full product from Need Validation through Concept generation, Detailed design/Engineering, Testing and Design } \\
\text { transfer with complete documentation as required by regulatory and production. } \\
\text { - Work with team from diff disciplines at peer a level and also with a junior team member }\end{array}$} \\
\hline
\end{tabular}


through these exams could aid in validating model efficacy and provide the students with an edge when it comes to employment opportunities [23].

This model calls for a diverse pedagogy that consists of classroom sessions and multidisciplinary team projects. The project team would be both hierarchical (inclusive of students from first through the fifth year of education) as well as a peer (inclusive of students from different core disciplines in the same year of schooling) in nature- Engaging with experts from engineering, medicine, industry and government to evaluate designs and provide constructive criticisms periodically will also enrich the program. Traditional self-study, seminars, and workshops would continue.

Other aspects to consider would be:

- Incentivising faculty and students towards innovation through recognition and monetary support

- Affiliating with medical, design, and business colleges for projects

- Faculty internships or sabbaticals aimed at spending time in Industry

- Collaborations with international academic institutes for course materials and international exchange opportunities

\section{Conclusions}

From the case study and interviews, it is clear that Medtech projects need interdisciplinary skills among developers and system engineers. Such a requirement holds good for any complex product-centric field. Both academia and industry agreed that the current Indian education model is not preparing students adequately. It was also seen that the burden to make up the difference is falling to the industrial sector, which impacts productivity. The current structure of higher education in India makes launching new programs for small niche industries challenging. The model proposed seems feasible as it does not disrupt the existing structure but adds a layer of interdisciplinarity and specialisation. This model could attract interested and capable individuals to deliver the quality of professionals needed by this industry in the small quantities it currently hires. The proposed model is conceptual in nature and has not been implemented before these publications. Thus, we cannot claim any conclusions on its utility and efficacy at this point. However, similar models have been implemented successfully in developed nations that have a flexible university system that allows for multiple diverse majors and minors. The next steps would be to gather further feedback and implement a pilot program of the model with an academic partner to allow a comprehensive assessment of its performance.
Acknowledgements The authors would like to thank all the academicians and industry experts for participating in the study.

\section{Compliance with ethical standards}

Conflict of interest The authors declare that they have no conflict of interest.

Ethical approval This article does not contain any studies with human participants or animals performed by any of the authors.

Informed consent Not applicable.

Open Access This article is distributed under the terms of the Creative Commons Attribution 4.0 International License (http:// creativecommons.org/licenses/by/4.0/), which permits unrestricted use, distribution, and reproduction in any medium, provided you give appropriate credit to the original author(s) and the source, provide a link to the Creative Commons license, and indicate if changes were made.

\section{References}

1. Sahu S, Panja S. Current Status and Challenges of Medical Device Innovations-Indian Perspective. 2017.

2. Rudrappa S, Agarkhed DV, Vaidya SS. Healthcare Systems: India. Quality Spine Care. Berlin: Springer; 2019. p. 211-24.

3. Frew SE, Kettler HE, Singer PA. The Indian and Chinese health biotechnology industries: potential champions of global health? Health Aff. 2008;27(4):1029-41.

4. Dang A, Sharma JK. Economics of Medical Devices in India. Value in Health Regional Issues. 2019;18:14-7.

5. Enderle J, Bronzino J. Introduction to biomedical engineering. Cambridge: Academic Press; 2012.

6. Van Dijk, TA. Ideology: A multidisciplinary approach. Sage; 1998.

7. Klein JT. Interdisciplinarity: History, theory, and practice: Wayne state university press; 1990.

8. Choi BC, Pak AW. Multidisciplinarity, interdisciplinarity and transdisciplinarity in health research, services, education and policy: 1. Definitions, objectives, and evidence of effectiveness. Clinical and investigative medicine. 2006;29(6):351.

9. Marjan Hummel J, Van Rossum W, Verkerke G, Rakhorst G. Medical technology assessment: the use of the analytic hierarchy process as a tool for multidisciplinary evaluation of medical devices. London: SAGE Publications Sage UK; 2000.

10. Drumheller P, Hubbell J. The biomedical engineering handbook. Boca Raton: CRC Press LLC; 2000.

11. Kremkau FW. Diagnostic ultrasound: principles and instruments. Philadelphia: WB Saunders Company; 2001.

12. Krishnamani R, DeNofrio D, Konstam MA. Emerging ventricular assist devices for long-term cardiac support. Nat Rev Cardiol. 2010;7(2):71.

13. Markham SK. The impact of front-end innovation activities on product performance. J Prod Innov Manag. 2013;30:77-92.

14. Figueiredo JFD. Interdisciplinarity and Design Conceptualisation: A Design Research Approach to the Early Stages of New Product Development. 2016.

15. INCOSE IMG. International Council on Systems Engineering. 2004.

16. Shah SGS, Robinson I. Benefits of and barriers to involving users in medical device technology development and evaluation. Int $\mathrm{J}$ Technol Assess Health Care. 2007;23(1):131-7. 
17. Lee I, Pappas GJ, Cleaveland R, Hatcliff J, Krogh BH, Lee P, et al. High-confidence medical device software and systems. Computer. 2006;39(4):33-8.

18. Gurbeta L, Dzemic Z, Bego T, Sejdic E, Badnjevic A. Testing of anaesthesia machines and defibrillators in healthcare institutions. J Med Syst. 2017;41(9):133.

19. Badnjevic A, Gurbeta L, Jimenez ER, Iadanza E. Testing of mechanical ventilators and infant incubators in healthcare institutions. Technol Health Care. 2017;25(2):237-50.

20. Badnjević A, Cifrek M, Magjarević R, Džemić Z. Inspection of Medical Devices: For Regulatory Purposes. Berlin: Springer; 2017.

21. Subramanian B, Kaulgud S, Joshi VR, Godbole G, Bahulikar M., Comparative study to determine the reliability and accuracy of the fetal lite electronic fetal monitor when compared with conventional cardiotocography. Communication Systems \& Networks
(COMSNETS), 2018 10th International Conference on; 2018: IEEE.

22. D'Souza R, Chaturvedi J, Tauheed AS, Jangir R, Sarovar A, Rodrigues D et al. Use of a Structured Process to Identify Compelling Unmet Medical Technology needs in Emergency Medicine and Critical Care in India. 2019.

23. List of IBSC Certified Biomedical Engineers. https://ibsc-amtz.in/ ibsc-certified-engineers/. Accessed 9 May 2019.

Publisher's note Springer Nature remains neutral with regard to jurisdictional claims in published maps and institutional affiliations. 